\title{
Investigatory behavior in the plains garter snake (Thamnophis radix) and several additional species
}

\author{
DAVID CHISZAR, TERRENCE CARTER, LESLIE KNIGHT, LORNA SIMONSEN, \\ and SHANNON TAYLOR \\ University of Colprado, Boulder, Colorado 80302
}

\begin{abstract}
Garter snakes (Thamnophis radix), hognose snakes (Heterodon platyrhinos), and rattlesnakes (Crotalus species) flick their tongues and crawl about in an open field containing no food or sexual (i.e., reproductive) odors. As Experiment I shows, the taxa differ reliably in both rate of tongue flicking and rate of locomotion. In Experiment II, garter snakes (Thamnophis radix) placed into an open field for 5 min showed more tongue flicking than snakes that were handled and placed directly back into their home cages, indicating that the first group was exploring the apparatus rather than responding only to handling. During Minutes 3 through 5 (Experiment III) in the open field, garter snakes emitted fewer tongue flicks than they did during the first minute, and after $20 \mathrm{~min}$, the rate of tongue flicking was virtually zero. However, snakes were capable of responding to presentation of new objects and/or odors, indicating that the previous response decrement was not derived from effector fatigue but rather from some habituatory process. Experiment IV revealed that satiated snakes habituated more rapidly than hungry snakes during exploration of the open field. Hence, exploratory behavior in these snakes is at least partially under the control of the same factors which mediate food-related appetitive activities.
\end{abstract}

Although researchers have long known about the involvement of the vomeronasal system (tongue and Jacobsen's organ) in snake and lizard investigatory behavior (e.g:, Carr, 1934), there are few systematic studies directed specifically at this system. Moreover, the major papers have been primarily concerned with the manner in which the system functions in locating potential mates (Noble, 1937) or food (Burghardt, 1966, 1967, 1969, 1970). Hence, the extent to which tongue flicking occurs during exploration of environments containing no food or sexual odors is unclear; it is also uncertain if the chemoreceptive tissues of the tongue and/or Jacobsen's organ are sensitive to molecules other than those arising from prey and mates. A main purpose of this investigation is to provide an answer to the first of these two questions.

At a more general level, the study by Glickman and Sroges (1966) provides additional inspiration for the present work. These investigators introduced novel objects (e.g., blocks of wood, pieces of plastic tube, lengths of chain, etc.) into the cages of various mammals and reptiles at the San Diego Zoo; and they recorded the number of visual orientations to these objects as well as the number of contacts each animal made with the objects (with mouth, nose, paws, etc.). Primates and carnivorous mammals had the highest mean scores for all objects, and

Requests for reprints should be sent to D. Chiszar, Department of Psychology, University of Colorado, Boulder, Colorado 80302. This research was supported in part by the M. M. Schmidt Foundation. reptiles had the lowest mean scores. In fact, the modal "curiosity" score for reptiles was zero. Hence, by these measures, reptiles appeared to exhibit little or no investigatory behavior when novel non-foodor-sex objects were placed into their home cages. However, any interpretation of these data must consider that the Glickman and Sroges measures were rather anthropocentric or at least mammalocentric, and that reptilian investigation may be completely overlooked if these measures are employed exclusively. The evolution of reptiles, particularly some snakes, has emphasized extreme silence and inactivity during hunting (i.e., ambushing); and, often, no orientation to prey is visible until the last instant (i.e., the strike), even though the snake is clearly aware of at least the relevant stimulus dimensions of the prey (Bullock \& Barrett, 1968; Cowles \& Phelan, 1958). Indeed, it is probably true that tongue flicking will occur far more frequently than any form of body contact in the appetitive behaviors of snakes and some lizards. Accordingly, we believe that Glickman and Sroges' data should not be interpreted as indicating a lack of "curiosity" in reptiles until these animals are examined with a more herpetocentric measure.

\section{EXPERIMENT I}

\section{Method \\ Subjects and maintenance conditions. Eight garter snakes (Thamnophis radix; $\overline{\mathrm{X}}$ weight $=43.4 \mathrm{~g}, \mathrm{SD}^{-}=16.1$; age $=$ approximately 16 months; captive born; no prior experimental history), eight rattlesnakes (five Crotalus viridis, one $C$. tigris, one}




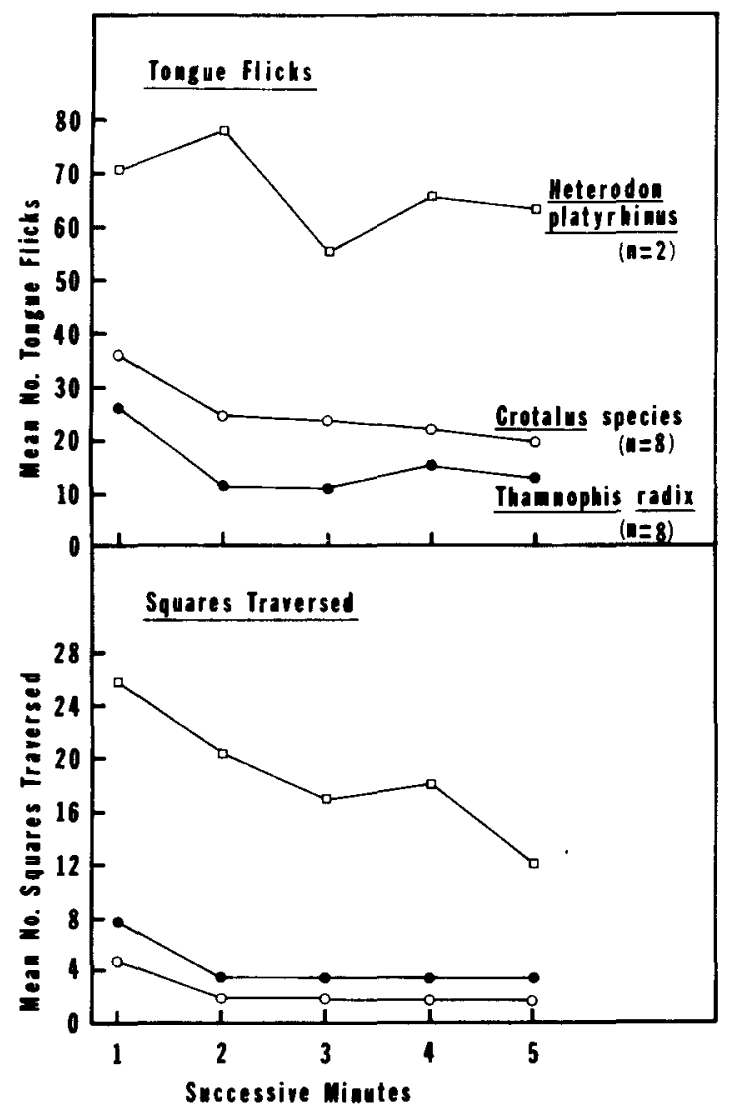

Figure 1. Mean number of tongue flicks (upper panel) and squares traversed (lower panel) as a function of successive minutes within days for three taxa of snakes observed in an open field (Experiment I).

C. enyo, and one $C$. atrox; $\overline{\mathrm{X}}$ weight $=309 \mathrm{~g}, \mathrm{SD}=75$; exact ages unknown but all animals were at least 3 years old; no prior experimental history), and two eastern hognose snakes (Heterodon platyrhınos, weights $=311,403 \mathrm{~g}$; exact ages unknown, but both animals were at least 2 years old; no prior experimental history) were employed in this study. The garter snakes were housed in two glass terraria $(50 \mathrm{~cm}$ long $\times 27.5 \mathrm{~cm}$ wide $\times 30 \mathrm{~cm}$ high) contanning rocks, sand, and water. The hognose snakes were housed in a wooden terrarium $(66.2 \times 38.7 \times 36.2 \mathrm{~cm})$, also containing rocks, sand, and water. The rattlesnakes were mantained in two large wooden cages $(180 \times 62.5 \times 80 \mathrm{~cm})$, each of which contained two or three additional rattlers of much larger size as well as rocks, sand, and water. Temperature in the garter snake terraria averaged $24^{\circ} \pm 2^{\circ} \mathrm{C}$ (room temperature in the lab). The hognose snakes received supplemental heat from a 40-W incandescent bulb to keep their cage above room temperature $\left(26^{\circ} \pm 1^{\circ} \mathrm{C}\right.$ during the light portion of the day/night cycle, $0700-2000 \mathrm{~h}$ ). The rattlesnake cages contained a centrally located, overhead infrared heat lamp ( $250 \mathrm{~W}$; illuminated between 0700 and $2000 \mathrm{~h}$ ), which created a temperature of $38^{\circ} \mathrm{C}$ on the sand immediately below and a gradient which dropped to $26^{\circ} \mathrm{C}$ in leftand rightmost areas of the cage floor. Although these temperature differences confound the species comparison, these conditions are needed for optimal health of the respective animals.

All snakes had lived in the laboratory for at least 2 months prior to this study. Garter snakes were offered two or three pieces ( $1 / 2$ to $1 \mathrm{~cm}^{3}$ of flesh per piece) of ocean perch fillets once weekly, and all individuals accepted this food readily. Hognose snakes were each given two frogs weekly when this food was avilable; otherwise, they were gently force-fed with neonatal mice (two or three per snake). Rattlesnakes were offered live adult mice (one to four per snake) once weekly; this food was readily taken, although some individuals ate only once every 2 or 3 weeks while others ate every week. No attempt was made to force-feed rattlenakes which did not feed voluntarily each week. Hence, some degree of variation in interval-between-feeding (t.e., "food deprivation") was unavoidable.

Apparalus and procedure. An open field constructed of plywood and coated with clear varnish was employed in Experiments I, II, and IV. The field was $100 \mathrm{~cm}$ long, $100 \mathrm{~cm}$ wide, $90 \mathrm{~cm}$ high, and the floor was marked off with a black felt-tip pen into $3616.5-\mathrm{cm}$ squares.

A trial began by placing a snake into the center of the floor. Two observers stood on opposite sides of the field; one recorded the number of tongue-flicks during each minute, and the other recorded the number of squares traversed by the snake's head during each minute. These records were made with the aid of hand-held, push-button counters. A trial lasted for $5 \mathrm{~min}$, after which the snake was returned to its home cage and the open field was cleaned (if the previous snake had cast visible excrement; otherwise, the field was cleaned only at the end of each day's use) in preparation for the next animal. Individuals of a particular taxon were run in a random order (determined by a table of random numbers) each day, but garter snakes were always run before rattlesnakes and the hognose snakes were always run last. ${ }^{1}$ Garter snakes and hognose snakes were transported to and from the open field by hand. Rattlesnakes were ti ansported with the and of a snake hook on which they balanced without struggling. Each snake was observed on five consecutive daily trals.

\section{Results}

The mean number of tongue flicks and squares traversed are plotted over minutes within days in the upper and lower panels of Figure 1, respectively. Both dependent variables in all taxa indicate an initial high rate of responding followed by a significant decline over the successive minutes (tongue flicks, $F=6.30 ;$ squares traversed, $F=13.45$; $\mathrm{dfs}^{2}=4 / 60$, ps $\left.<.01\right)$. The main effects of taxa were also significant (tongue flicks, $F=11.73$; squares traversed, $\mathrm{F}=7.71 ; \mathrm{dfs}=2 / 15$, ps $<.01$ ); and Duncan's new multiple range test revealed that each taxon was significantly different from each other taxon by both dependent variables. The main effect of Days was not reliable for either measure, indicating that overall rate of responding remained fairly constant over days, and the Days effect did not interact with either Minutes within Days or Taxa. Hence, the pattern of differences visible in Figure 1 was reproduced on each of the 5 days of the study.

\section{Discussion}

The higher rate of responding by $\boldsymbol{H}$. platyrhinos is probably related to physiological (especially hormonal) specializations, which are presumed to be the basis for the bufophagus diet of these animals. Specifically, Smith and White (1955) and Spauer and Smith (1971) showed that the adrenal glands of hognose snakes are considerably larger per unit body weight than various control (i.e., nonbufophagus) 
species; and they suggested that enlarged adrenals are associated with higher circulating titers of epinephrine, such that additional amounts derived from the skin glands of toads do not represent serious perturbations. It is easy to understand high activity levels in these animals, since high titers of adrenal hormones would be expected to potentiate motor performance. (Indeed, our specimens of $H$. platyrhinos seem more active than other species in the home cage as well as in the open field.)

The difference between tongue-flick rates of rattlesnakes and garter snakes, although statistically reliable in this study, should not be regarded as a taxon-discriminating character for reasons which will be documented in Experiments II and IV. (Briefly, Experiment II reveals that young garter snakes show far higher response rates than do older ones; Experiment IV shows that food deprivation exerts profound incremental effects on response rate.) However, it is of interest that rattlesnakes crossed fewer squares than garter snakes, even though the former tongue-flicked at a higher rate. This reveals that the high correlation between tongue-flick rate and square-traversing rate within subjects and species (Chiszar \& Carter, 1975) should not be generalized to between-species comparisons.

The most important finding of this study is the fact of high initial rates of responding followed by what appears to be habituation. This implies that the snakes were exploring stimulus characteristics of the open field. However, it is possible that the initial response rates are a function of handling and transportation rather than of stimuli arising from the apparatus. Experiment II was designed to test this possibility.

\section{EXPERIMENT II}

\section{Method}

Subjects and maintenance and conditions. Ten experimentally naive garter snakes (Thamnophis radix; approximate age $=4$ to 5 months) were donated by Mr. I. Solomon of Boulder, Colorado. These animals were not more than 6 months old and weighed an average of $22.0 \mathrm{~g}(\mathrm{SD}=8.0)$. Each individual was housed in a plastic terrarium $(31.2 \mathrm{~cm}$ long $\times 17.5 \mathrm{~cm}$ wide $\times 10 \mathrm{~cm}$ high) with paper bedding, a rock, and water. Temperature and photoperiod were identical to those described for garter snakes in Experiment I. Subjects had been living in these terraria for approximately 1 month prior to this study, during which they were offered pieces of fish flesh in the same manner as in Experiment I. These snakes had probably not been handled more than five or six times since they were born.

Apparatus and procedure. On each of 8 consecutive days, the snakes were treated in the following manner. Individuals were observed for $2 \mathrm{~min}$ in their home cage and the number of tongue flicks emitted during each minute was recorded. Next, snakes of Group A were removed from their terraria and placed into the open field (same apparatus and general procedure as in Experiment I) for $5 \mathrm{~min}$, and the number of tongue flicks emitted during each minute was recorded. Individuals of Group B were removed from their terraria, held for $3 \mathrm{sec}$ (the same length of tıme required to transfer a Group A snake to the open field) and then placed directly back into their terraria where tongue flicks were again recorded after each of $5 \mathrm{~min}$. Hence, these snakes were handled but not exposed to the novel stimuli arising from the open field.

\section{Results}

The mean number of tongue flicks emitted during minutes within days by both groups are plotted in Figure 2. No tongue flicks were observed during the $2 \mathrm{~min}$ prior to handling. Handling exerted a dramatic effect on this measure, as can be seen by comparing the means on Minutes 1 and 2 for Group B individuals (handled and placed back into home cages) with their means for the 2 min prior to disturbance $(t=6.17, \mathrm{df}=4, \mathrm{p}<.01)$. However, it is also clear that the open field produced far more tongue flicking than could be accounted for by handling alone $(F=19.32$, $\mathrm{df}=1 / 8, \mathrm{p}<.01)$. This difference represents an operational definition of exploratory behavior in garter snakes.

The decline in tongue-flick rate over minutes within days was also reliable $(F=64.33, \mathrm{df}=4 / 32$, $\mathrm{p}<.01$ ), and this effect did not interact with Days $(\mathrm{F}=1.29, \mathrm{df}=28 / 224, \mathrm{p}>.05)$, suggesting that snakes of both groups behaved similarly on each of the successive days. However, the main effect of Days was significant $(F=2.94$, df $=7 / 56, p<.01)$, indicating that the absolute level of responding decreased over successive exposures to the open field.

\section{Discussion}

The overall response rate of the young snakes employed in Experiment II was higher than that of the older ones used in Experiment I. This differ-

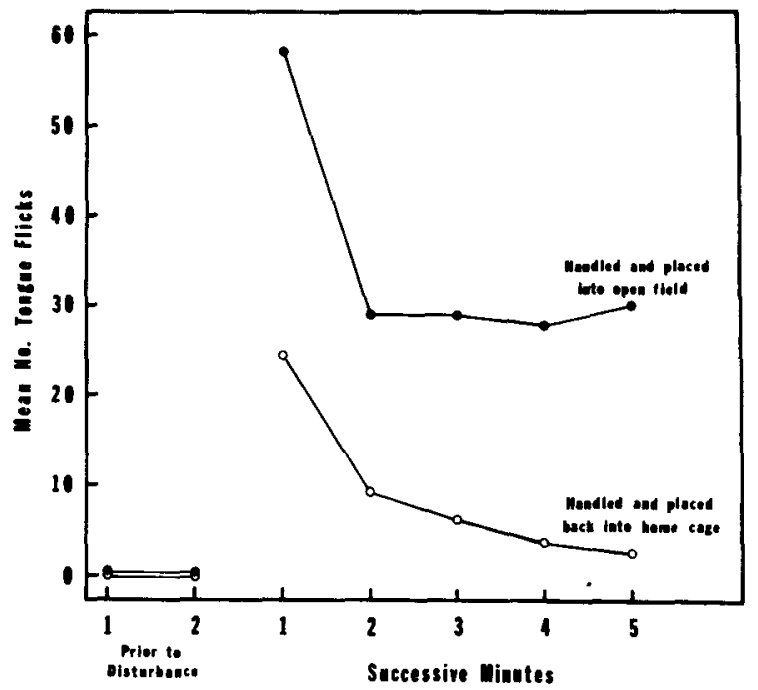

Figure 2. Mean number of tongue flicks by garter snakes in the home cage prior to disturbance and for 5 successive minutes after either (A) being placed into an open field (solid circles) or (b) being handled for 3 sec and placed back into home cage (open circles) on 8 successive days (Experiment II). 
ence might derive from some physiological effect of age or from some effect of duration of time in captivity. We suggest that both factors are involved and that the separation of their respective contributions would shed important light on the effects of domestication in reptiles.

This experiment has shown that garter snakes respond to the open field with greater frequency of tongue flicking than the handling controls, suggesting that stimulus characteristics of the open field are, in fact, being investigated by the animals. Since food and sexual odors were not present in the open field, the tongue-flicking shown by Group A snakes cannot be explained by the eliciting effects of such consummatory objects. ${ }^{2}$ Also, since observers were equally visible to snakes of Groups A and B, it does not seem reasonable to explain the performance of Group $A$ on the basis of uncontrolled effects of observer cues. Hence, we conclude that Experiment II provides evidence for the existence of a general type of exploratory behavior in garter snakes.

In Experiments I and II, the initial high rates of tongue flicking were eventually followed by decreases in response rate. Although we have suggested that this "appears" to be habituation, it is possible that muscular fatigue resulting from the high initial rate of tongue flicking is responsible for the subsequent decline. Experiment III is directed to this point.

\section{EXPERIMENT III}

\begin{abstract}
Method
Subjects and maintenance conditions. Six garter snakes (approximate age $=7-8$ months) weighing an average of $38 \mathrm{~g}$ (SD $=7.2$ ) were donated by the same source described in Experiinent 11. The animals were maintained in a single terrarium, $50 \mathrm{~cm}$ long $\times 27.5 \mathrm{~cm}$ wide $\times 30 \mathrm{~cm}$ high, and temperature, photoperiod, and feeding schedule were identical to those described for garter snakes in Experiment I. The snakes lived under these conditions for approximately 2 months prior to the beginning of this study.

Apparatus and procedure. The open field was constructed entirely from glass $(90.0 \mathrm{~cm}$ long $\times 45.0$ wide $\times 45.0 \mathrm{high})$, except that a piece of heavy white construction paper covered the floor. The paper was marked off with a felt-tip pen into $15-\mathrm{cm}$ squares.

A trial began by placing an individual snake into the center of the floor. All tongue flicks and squares traversed by the head were recorded for the following $20 \mathrm{~min}$. This relatively long period was used to allow ample time for the initial high rate of tongue flicking to decrease. Following the 20th min, a vessel $(31.2 \mathrm{~cm}$ long $\times 17.5$ wide $\times 10$ high) containing either $4.0 \mathrm{~cm}$ water or $4.0 \mathrm{~cm}$ water plus suspended particles of ground lish flesh was gently placed into the open field and remained iherein for an additional $20 \mathrm{~min}$. Three snakes received the water, and three received the water plus fish flesh. Number of tongue Ticks and number of squares crossed by the head were recorded during this second 20 -min period for each snake.
\end{abstract}

\section{Results}

The mean number of tongue flicks and squares Iraversed for all six snakes during the first $20 \mathrm{~min}$

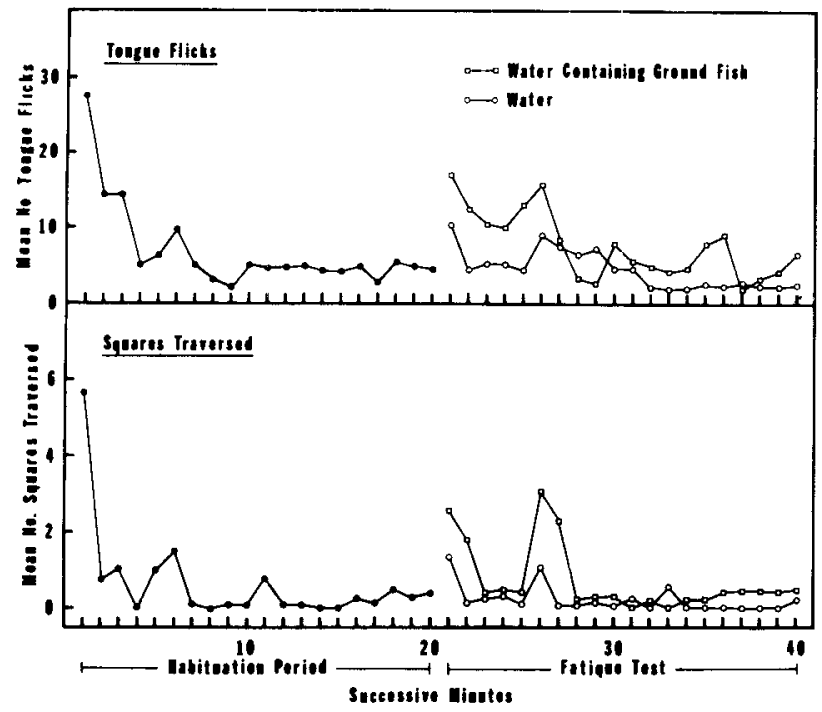

Figure 3. Mean number of tongue flicks (upper panel) and squares traversed (lower panel) emitted by six garter snakes during 20 min of exposure to an open field, followed by the introduction of a vessel containing either plain water $(n=3)$ or water plus ground fish particles $(n=3)$. These vessels remained in the open field for an additional 20 min (Experiment III).

are shown in the left panels of Figure 3. There were no differences during this period between the means of the snakes receiving water and those receiving water plus fish particles (tongue flicks, $F=2.80$; squares traversed, $F=1.31 ; \mathrm{dfs}=1 / 4 ; \mathrm{ps}>.05$ ). The declines apparent in both tongue-flicking and square traversing over the 20 -min period were significant (tongue flicks, $F=8.60$; squares traversed, $F=14.53 ; \mathrm{dfs}=19 / 76 ; \mathrm{ps}<.01)$, and the decrements seemed complete after the first $10 \mathrm{~min}$, although occasional responses were seen thereafter. When water or water plus fish particles was introduced, all snakes oriented toward the vessels and there were immediate increases in both response measures (even though no snakes moved toward the vessels). Comparing the tongue-flick rate for the $5 \mathrm{~min}$ preceding with $5 \mathrm{~min}$ following the introduction of the vessels revealed a significant main effect of the within-subject factor $(F=8.50 ; \mathrm{df}=1 / 4, p<.05)$. That is, snakes showed reliably less tongue flicking during Minutes 15 through 20 than during Minutes 21 through 25 , regardless of the contents of the vessel introduced into the open field. This was also true for the square-traversing measure $(F=10.65$, $\mathrm{df}=1 / 4 ; \mathrm{p}<.05)$. The apparent difference between the two groups of snakes was not statistically reliable for either dependent variable during Minutes 21 through 30 (tongue flicks, $F=2.70$; square traversing, $F=1.61 ; \mathrm{dfs}=1 / 4 ; \mathrm{ps}>.05$ ).

\section{Discussion}

This study shows that the reduction in tongue flicking and square traversing evidenced during the 
first period of open-field exposure is not based entirely upon fatigue of the muscles controlling the tongue or the neck. If this were so, then presentation of a new stimulus after the 20th minute could not have initiated an elevated rate of responding. Of course, even if muscular fatigue occurred during Minutes 1 through 10 , some recovery could have occurred during Minutes 11 through 20 when a stable, low rate of responding (i.e., 2 to 4 flicks $/ \mathrm{min}$ ) was maintained. However, this seems unimportant because garter snakes trailing food have been observed to flick their tongues at a rate of 20-40 flicks/min for at least 30 min (Chiszar, Scudder, \& Knight, in press). This, in turn, further justifies our conclusion that the response decrement during Minutes 1 through 20 represents habituation.

The fact that water containing fish particles did not produce more tongue flicking than plain water is puzzling. Since the present differences were in the "right" direction, it can be suggested that larger sample size would give significant differences. Also, perhaps degree of hunger might be an important interacting factor, such that well-fed snakes do not respond any more to food cues than to other stimuli which are suddenly introduced into the open field. Indeed, well-fed snakes might be generally less responsive than snakes which have been fasted for increasing periods of time (Burghardt, 1970). Accordingly, it is necessary to analyze the effects of food deprivation on open-field behavior before drawing conclusions about reptilian exploration or, more specifically, about the effects of foodrelated cues on exploration. Experiment IV recorded the numbers of tongue flicks and squares traversed in the open field by snakes under different feeding schedules.

\section{EXPERIMENT IV}

\footnotetext{
Method

Subjects and maintenance conditions. Nine garter snakes (approximate age $=2$ years; $\overline{\mathrm{X}}$ weight $=60 \mathrm{~g}, \mathrm{SD}=12.3$ ) were employed in this study. These animals were randomly divided into three groups $(n=3)$, and each group was housed in a separate terrarium $(50 \mathrm{~cm}$ long $\times 27.5 \mathrm{~cm}$ wide $\times 30$ high) with rocks, sand, and water. Temperature, photoperiod, and prevous feeding history were identical to those described for garter snakes in Experiments I, II, and III. However, after a regular weekly feeding day, Group A was offered food on each succeeding day, Group B was offered food once after 5 days, and Group $C$ was not fed for the 10-day period of this study.

Apparatus and procedure. Each snake was placed into the open field (same one employed in Experiments I and II) for $5 \mathrm{~min}$ on each of 10 successive days. Number of tongue flicks and squares traversed were recorded after each minute. General procedure was identical to that described in Experiment I. Group A snakes were fed between 1200 and $1300 \mathrm{~h}$. Group B anımals were fed only once during the 10-day period, and the interval between feeding and open-field observation on that day was the same as for Group A (about $30 \mathrm{~min}$ ).
}

\section{Results}

Mean numbers of tongue flicks and squares traversed are plotted over minutes within days in the upper and lower panels of Figure 4, respectively. All days were pooled for this presentation. The main effect of successive minutes is obvious in both measures (tongue flicks, $\mathrm{F}=11.64$, squares traversed, $\mathrm{F}=36.03 ; \mathrm{dfs}=4 / 24 ; \mathrm{ps}<.001)$. Also, the differences between the groups are equally obvious. The Group main effect was significant for the tongueflick measure $(F=5.43 ; \mathrm{df}=2 / 6, p<.05)$, while squares-traversed revealed a significant Group by Minutes interaction $(F=3.05, \mathrm{df}=8 / 24 ; \mathrm{p}<.05$; group main effect, $F=1.85 ; \mathrm{df}=2 / 6, \mathrm{p}>.05$ ). The reason for this discrepancy between the dependent variable is fairly clear in Figure 4 . The tendency was for a high initial rate of responding during the first minute, to be followed by a greater decline in Group A than in Groups B and C. This differential decline is clearer in squares traversed than in tongue flicks. In general, it seems justifiable to conclude that well-fed snakes explored less than fasted ones, particularly during Minutes 2 through 5. (Post hoc

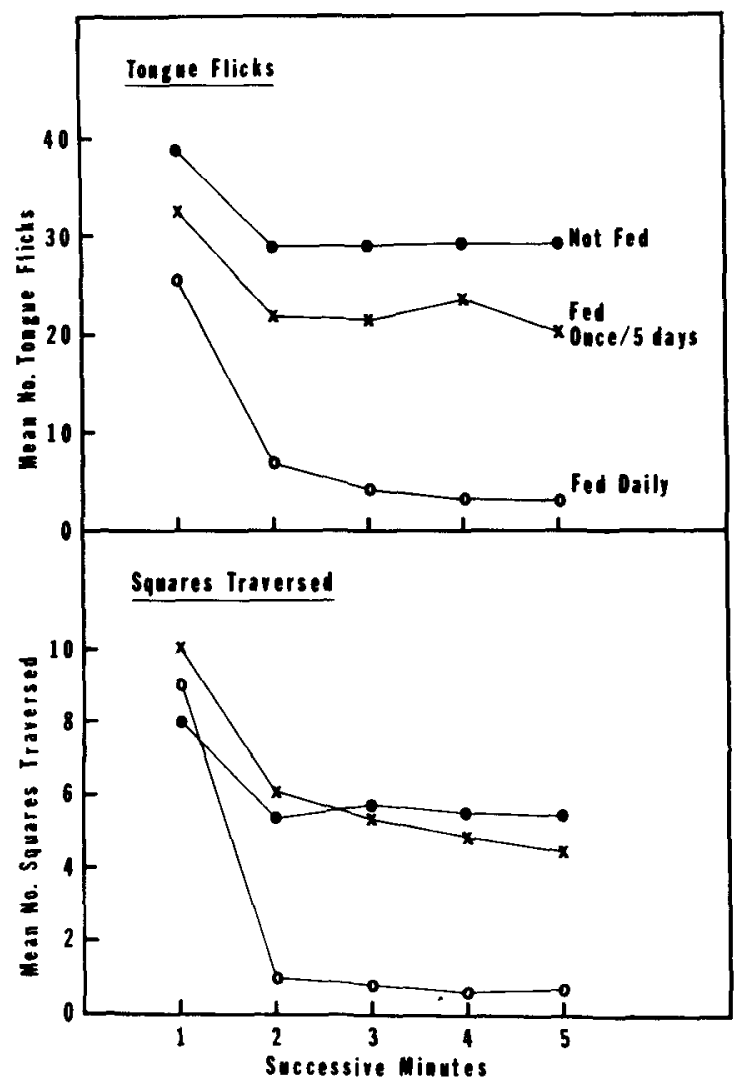

Figure 4. Mean number of tongue flicks (upper panel) and squares traversed (lower panel) over minutes within days for three groups of garter snakes. Individuals of Group A were offered food daily, those of Group B were fed once ( 5 days after the start of the study), and snakes in Group $C$ were fasted for the entire 10-day period of the study. 
tests revealed that Groups $B$ and $C$ did not differ on either dependent variable, but that both of these groups differed from Group A during Minutes 2 through 5 on both dependent variables.)

The main effects of Days did not attain significance for either dependent variable (tongue flicks, $F=1.11$, squares traversed, $\mathrm{F}=0.84 ; \mathrm{dfs}=9 / 54 ; \mathrm{ps}>.05$ ), nor did Days interact significantly with minutes within days (Fs $<1)$. Hence, the functions relating mean number of tongue flicks or squares traversed to minutes for each group was repeated without change on each of the 10 successive days of this study. This implies that long-term habituation (i.e., a decrease in responding over days) did not occur, even though considerable decreases in responding occurred within each daily open-field trial.

\section{Discussion}

This study reveals that open-field exploration is greatly influenced by hunger, and this, in turn, suggests that exploration is partly an appetitive behavior serving to increase the likelihood that a hungry snake will come into contact with food items (if any are available in the environment). However, the fact that response rate is high during the first minute of open-field trials regardless of hunger levels suggests that initial investigatory activity is independent of the appetitive substrate and is, in fact, dependent upon effects of handling plus stimuius novelty (see also Burghardt, 1969).

In general, the experiments reported in this paper provide evidence that snakes explore novel stimuli and at least some form of short-term habituation occurs, probably reflecting stimulus satiation or temporary familiarity with the stimulus milieu (particularly the chemo-stimulus dimensions). Hence, by employing "herpetocentric" measures of investigatory behavior, we find it necessary to reverse the conclusions drawn about the absence of "curiosity" in reptiles by Glickman and Sroges (1966). It is important, however, to recognize that "curiosity" as it has been operationalized in this study is almost entirely dependent upon the reptilian vomeronasal system. We have no ideas about the extent to which other sensory tissues might play active informationgathering roles during exploration of novel environments. Moreover, we have no knowledge about the manner in which information derived from other modalities interacts with vomeronasal cues or about the manner in which hunger influences other modalities. Thus, a great deal of work remains to be done in order to complete the conceptualization of reptilian "curiosity" which has been developed in this report.

\section{REFERENCES}

Bullock, T. H., \& BarRetT, R. Radient heat reception in snakes. Communucatıons in Behavioral Biology, 1968, 1, 19.29.

Burchardt, G. M. Stimulus control of the prey attack response In naive garter snakes. Psychonomic Science, 1966, 4, 37-38.

Burghardt, G. M. Chemical cue preferences of inexpenenced snakes: Comparative aspects. Science, 1967, 157, 718-721.

Burghardt, G. M. Comparative prey-attack studies in newborn snakes of the genus Thamnophis. Behaviour, 1969, 33, 77-114.

Burghardt, G. M. Chemical perception in reptiles. In J. W. Johnston, Jr.. D. G. Moulton, and A. Turk (Eds.), Communication by chemical signals. New York: AppletonCentury-Crotts, 1970.

CARr, A. F., JR. Notes on the habits of the short-tailed snake, Stilosoma extenuatum Brown. Copeia, 1934, 138-139.

Chiszar, D., \& Carter, T. Reliability of individual differences between garter snakes (Thamnophis radix) during repeated exposure to an open field. Bulletin of the Psychonomic Socuty, 1975, 5, 507.509.

Chiszar, D., Scudder, K. M., \& KNight, L. Rate of tongue llickıng by garter snakes (Thamnophis radix haydeni) and rattlesnakes (Crotalus v. viridis, Sistrurus catenatus tergeminus and $S$. c. edwardsi) during prolonged exposure to food odors. Behavioral Btology, in press.

Cowles. R. B., \& Phel.an, R. L. Olfaction in rattlesnakes. Copela, 1958, 77-83.

Glickman, S. E., \& Sroges, R. W. Curiosity in 200 animals. Behaviour, 1966, 24, 151-188.

Noвle, G. $K$. The sense organs involved in the courtship of Storeriu. Thumnophis and other snakes. Bulletin of the American Museum of Natural History, 1937, 73, 673.725.

Sмгтн, H. M., \& Whiтe, F. M. Adrenal enlargement and its signiticance in the hognose snake (Heterodon). Herpetologica, $1955,11,137-144$.

Spaur, R., \& Smith, H. M. Adrenal enlargement in the hognose snake, Heterodon platyrhinos. Joumal of Herpetology, $1971,5,197.199$.

\section{NOTES}

1. Reliable individual differences were observed within each taxon in absolute rate of responding (both tongue flicking and square traversing) in all experiments reported here (see also Chiszar \& Carter, 1975). We found no evidence of systematic "order effects" in any study reported hetê, indicating that subjects were not influenced by cues (odors) arising from previous individuals.

2. Since the present snakes were much too young to reproduce, we can safely assume that odors indicative of the reproductive condition were not secreted in the open field or in the home cage. It is possible, however, that nonreproductive, but sexspecific, odors of these immature specimens could have been left in the open field (but see footnote 1).

(Received June 9, 1975; revision received December 23,1975 .) 